OPEN ACCESS

Edited by:

Stefinee Pinnegar,

Brigham Young University,

United States

Reviewed by:

Jessica Erin Charles,

Bank Street College of Education,

United States

Leonardo Glasserman-Morales,

Monterrey Institute of Technology,

Mexico

${ }^{*}$ Correspondence:

Ronghua Zhang

691153930@qq.com

Aibao Zhou

zhouab@nwnu.edu.cn

Specialty section: This article was submitted to

Teacher Education,

a section of the journal

Frontiers in Education

Received: 12 October 2018

Accepted: 23 January 2019

Published: 07 February 2019

Citation:

Zhang $R$, Jiang $Y$, Dang $B$ and Zhou $A$ (2019) Neuromyths in Chinese

Classrooms: Evidence From

Headmasters in an Underdeveloped Region of China. Front. Educ. 4:8. doi: 10.3389/feduc.2019.00008

\section{Neuromyths in Chinese Classrooms: Evidence From Headmasters in an Underdeveloped Region of China}

\author{
Ronghua Zhang *, Yanfei Jiang, Baobao Dang and Aibao Zhou* \\ School of Psychology, Northwest Normal University, Lanzhou, China
}

Neuromyths are misinterpretations of neuroscientific knowledge that may negatively affect the development of science-based education. They arise from complex scientific advances that are often communicated in a simplified form by the media and consumed by the untrained public, including education professionals, in a variety of cultural and social contexts. To better understand such variations, the present research used a questionnaire to survey the belief in neuromyths among headmasters in Gansu province in northwestern China. In all, 253 headmasters of the elemental and middle school participated in the survey, the results showed that headmasters in Gansu province were interested in neuroscience and that they commonly believed neuromyths. The most widespread neuromyths were those about learning styles, rich environments for pre-school children, and exercise to improve brain function. The educators' personal backgrounds, such as level of education and school type, may be predictive of their belief in neuromyths. Our results indicated that headmasters must be alert in attempting to apply neuroscience laboratory results to classroom teaching.

Keywords: neuromyths, education, China, headmaster, neuroscience

\section{INTRODUCTION}

The ongoing debate on how findings from neuroscientific laboratory research should be applied in classrooms has drawn attention to misinterpretations of neuroscientific findings, referred to as neuromyths (Hook and Farah, 2013; Tardif et al., 2015). The Organization of Economic Co-operation and Development (OECD) Brain and Learning Project defines neuromyths as "misconception[s] generated by a misunderstanding, a misreading or a misquoting of facts scientifically established (by brain research) to make a case for use of brain research in education and other contexts" (OECD, 2002, p. 111).

It is not surprising that neuromyths are widespread across a variety of schools and have negative effects in the classroom. Marta et al. (2016), through a meta-analysis of previous studies related to neuromyths, have found that some neuromyths are consistent across countries; for instance, the most widespread neuromyth may be the idea that children learn better when they receive information in their preferred learning style (e.g., the visual, auditory, kinesthetic and [VAK] styles). Such neuromyths might mislead teachers to over-stress the manner in which they present information. Another typical neuromyth is that the environment or exercise might improve brain functions. Such a belief might lead to wasting money, time, and effort that could be better spent on evidence-based practices (Dekker et al., 2012). Previous studies have shown that neuromyths are widespread across countries and schools; because teachers are motivated by the desire to improve 
student learning by using neuroscience, their distorted understanding of neuroscientific research findings may have adverse effects on their educational practice (Dekker et al., 2012).

Over the past decade, neuromyths have received much attention, owing to increasing efforts to build bridges between the neuroscience laboratory and the classroom (Ansari and Coch, 2006). Several authors have investigated the origin of neuromyths by using questionnaire data (Howard-Jones et al., 2009; Dekker et al., 2012; Hook and Farah, 2013; Tardif et al., 2015), and others have performed literature reviews (HowardJones, 2014). They have found that neuromyths might occur in all stages of the transmission of neuroscience knowledge from the laboratory to the classroom. In the laboratory, some neuromyths occur because certain laboratory results are believed to be true until they are disproven by new evidence (Pasquinelli, 2012), while the old beliefs that might be wrong is hard to change; the popular media contribute to some neuromyths when they attempt to disseminate neuroscience knowledge but intentionally or unintentionally distort or misconstrue the scientific facts or jargon (Rato et al., 2013); and school staff members, such as teachers, believe some neuromyths that might have a negative effect in the classroom (Marta et al., 2016). In brief, neuroscientists, mass media, and educators use different terminology and language, thus potentially creating neuromyths when educators attempt to apply neuroscience knowledge to the classroom (Figure 1 showed the origin of neuromyths in 3 stages).

Previous studies have examined neuromyths in the context of western culture or in developed countries. However, to our knowledge, there has been no research investigating neuromyths in underdeveloped regions of China. A survey of 238 teachers in the more developed eastern part of China showed similarities as well as differences between China and Europe (Pei et al., 2015). According to this study, Chinese teachers hold beliefs in the neuromyths of learning style and hemisphere differences similar to those held by teachers in Europe, but they are more enthusiastic about myths related to attention and vigorous exercise which were differ from European teachers. These findings indicate that cultural differences and educational investment in understanding the brain (Pei et al., 2015) might cause different neuromyths. To investigate such potential differences, we conducted our survey in Gansu province, one of the most underdeveloped provinces in China [in 2000, Gansu province ranked second to last in terms of GDP per capita at 3,838 yuan (468 dollars), whereas Shanghai topped the list at 27,187 yuan (3,315 dollars)] (Chen, 2002). Beyond the province's economic rank, its educational environment is different from that of other provinces. According to educational data published by the Ministry of Education of the People's Republic of China (2013), the value of fixed school assets in 2013 was 67.83 billion yuan (nearly 10 billion dollars) in Shanghai but only 18.46 billion yuan (nearly 3 billion dollars) in Gansu. The different economic environment affected many aspects of education; for instance, the lower educational investment might decrease investment in interdisciplinary collaboration between neuroscientists and educators, which is an important protect factor in telling neuromyths from neuroscience (Marta et al., 2016).

Although almost all previous studies of neuromyths have surveyed their prevalence among teachers (Chen, 2002; HowardJones et al., 2009; Dekker et al., 2012; Hook and Farah, 2013), we focused on headmasters. There is no doubt that teachers play an important role in applying neuroscientific findings to the classroom; however, headmasters are in a unique position: many have been teaching for a long period and thus have extensive practical experience in the classroom; in addition, they are policy makers in their schools. As previous research showed, neuromyths would lead to the waste of educational resources. For the headmasters who believed in neuromyths and willing to make it into practice, it is even worse. For instance, the headmasters who believed in the Mozart Effect (Bangerter and Heath, 2004) may spend more money on products based on it; while the headmasters who believed in the learning style may require school teachers designed courses based on it. If the headmasters use the neuromyths to guide education in their schools and can't receive positive results, they may lose confidence of the real neuroscience which will be obstacle for building bridge between neuroscience and education. Because the development of neuroeducation depends on the support of policy makers (Oliver, 2011), it is meaningful to investigate the prevalence of neuromyths among headmasters.

This study investigated the prevalence of neuromyths among headmasters in Gansu province, China, by using a questionnaire survey. We hypothesized that headmasters in this underdeveloped region would believe in neuromyths somewhat similar to those found in eastern China and in Europe because we expected some cross-cultural consistency (Howard-Jones, 2014). However, owing to cultural and economic background differences, we also expected to find some features specific to this sample (Pei et al., 2015).

\section{METHODS}

\section{Participants}

The participants were all headmasters of state-owned schools in Gansu province, totally 253 (68 females, 26.9\%) were involved in the survey. Mean age of 41.40 years $(S D=7.64)$. Fortythree (35 females) were from pre-schools, 140 (29 females) were from primary schools (grades 1-6), and 70 (4 females) were from secondary schools (grades 7-12). Fifty-seven (22.5\%) of the headmasters worked for schools located in urban areas, whereas $194(77.1 \%)$ worked in rural schools (1 missing data). Fifty-two (20.6\%) were in key schools, whereas 199 (78.7\%) were in general schools ( 2 missing data) (key schools obtain more resourcessuch as educational funds, excellent teachers and students, and cooperative projects-than do the general schools).

In contrast to the educational policy in some western countries, the school headmaster in China is also a teacher (Hongshan, 2012). The headmasters provided background information about their professional teaching qualifications (25 technical schools, 71 junior colleges, 157 colleges), their number of years of teaching experience $($ Mean $=18.77, S D=8.52)$, and the subjects that they teach (science, art, others). The 


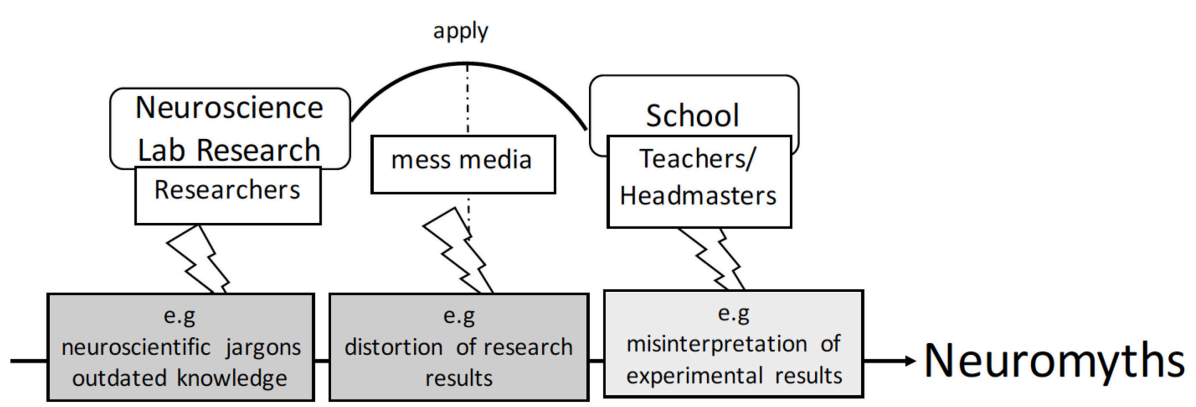

FIGURE 1 | Neuroscientists, the mass media and educators might all contribute to neuromyths.

Ethical Committee of School of Psychology, Northwest Normal University approved the study.

\section{Questionnaire}

The study used a questionnaire based on Dekker et al. (2012) and Howard-Jones et al. (2009) to explore the correlation between the headmaster demographic variables and neuromyths. The questionnaire comprised 40 statements about neuroscience knowledge, including 15 neuromyths and 25 (correct) statements about general knowledge of neuroscience (GKN); the latter consisted of 10 statements about the mind-brain relationship and 15 statements regarding other neuroscience knowledge. For each statement, we asked about the extent to which the headmaster agreed or disagreed: the participants' responses were on a 4-point Likert scale: "1-strongly agree," "2-agree," "3-disagree," and "4-strongly disagree" (Tardif et al., 2015).

We listed three more questions in a supplementary section to be completed after they finished the 40 statements: (1) Please choose the statement that you think has the closest relationship with educational practice for the 40 statements you've just read; (2) Please rate how often you use such knowledge to improve your teaching ("1-often use," "2-occasionally use," "3-never use"); and (3) If you know of any neuroscientific knowledge that was not listed above, please add it.

The participants in the present study are all native Chinese speakers, so the questionnaire was translated from English to Chinese in four steps. First, three psychology postgraduates translated the questionnaire from English to Chinese, producing the "rough draft." Second, two postgraduates who majored in English modified the rough draft in aspects of language use, producing a "modified version." Third, to confirm the accuracy of the translation, the modified version was translated back into English by an experienced English teacher and a psychology postgraduate (who had not previously seen the questionnaire). After comparing the latter translation with the original questionnaire, we made minor modifications to the modified version and obtained the "pre-test version." Fourth, 17 participants (all college teachers) took the questionnaire as a pre-test and answered questions such as "Do you have any questions about the questionnaire?" "Is any part of the questionnaire unclear?" and "Do you have any suggestions about the questionnaire?" Because no participants indicated that the questionnaire was difficult to understand, we did not make changes to the pre-test version and thus produced the final version of the questionnaire.

\section{Procedure}

All participants were participating in a school safety training meeting held by the local Education Bureau when the data were collected. All headmasters completed the questionnaire on paper. The experimenter introduced the questionnaire and remained in the classroom while the participants completed it. The average time for completing the questionnaire was $15 \mathrm{~min}$.

\section{Data Analyses}

The data were analyzed with SPSS 19.0 for Windows. In addition to the general description of the questionnaire, the correlations between GKN and neuromyths were obtained by using the correct scores for each participant. Then, to explore the possible predictors of neuromyths, a linear regression analysis was conducted by using the scores of neuromyths as a dependent variable and the headmasters' backgrounds (gender, age, professional qualifications, number of years of teaching, subject areas, school types, and school location) as independent variables.

\section{RESULTS}

The results showed that most participants were interested in neuroscience, even if they lacked the opportunity to learn about it. According to the questionnaire, $88 \%$ (221) of the headmasters thought that neuroscience is useful for educational practice. In terms of training, only 21 (8\%) participants had taken neuroscience courses, and 24 (10\%) subscribed to neurosciencerelated magazines.

\section{Prevalence of Neuromyths}

There was considerable variation in the participants' replies to statements of neuromyths, as illustrated in Table 1. In total, for 8 out of the 15 statements, fewer than $50 \%$ of the responses were correct. The statement "Individuals learn better when they receive information in their preferred learning style" received the lowest correct scores, with only $6.4 \%$ of the participants correctly disagreeing. For 7 statements, more than $50 \%$ of the responses 
were correct. The statement with the most correct responses was "Individual learners show preferences for the mode in which they receive information," with which $88.9 \%$ of participants correctly agreed.

\section{General Knowledge of Neuroscience}

There were 25 statements for GKN, including topics such as the mind-brain relationship and biological knowledge of the brain. The results showed that for 6 of the 24 statements, fewer than $50 \%$ of the answers were correct $(\min =16.9 \%$, $\max$ $=49.8 \%, M=33.25 \%$ ), whereas for the other 19 statements, more than $50 \%$ of the answers were correct $(\mathrm{min}=52.4 \%$, $\max =96.8 \%, M=81.18 \%)$. According to the survey, a large percentage of the headmasters believed that the environment can shape mental ability. For instance, $81.1 \%$ disagreed or strongly disagreed with the statement "Mental capacity is hereditary and cannot be changed by the environment or experience," and $90.1 \%$ agreed or strongly agreed with the statement "One's environment can influence hormone production and, in turn, personality." A considerable portion of the headmasters also perceived that mental ability or performance can be improved through exercise. The statements "Vigorous exercise can improve mental function" and "Performance in activities such as playing the piano improves as a function of hours spent practicing" received 83.4 and $91.7 \%$ agree or strongly agree ratings, respectively.

In the supplementary part of the questionnaire, only $7(2.7 \%)$ of the 253 headmasters chose a statement that they thought might be related to teaching, and only 2 indicated that they used (or occasionally used) some of the statements. None of the participants added any neuroscience knowledge that was not already listed in the questionnaire.

\section{The Correlation of Neuromyths and General Knowledge of Neuroscience}

Because the correct responses were obtained on a 4-point Likert scale, we computed Pearson correlation coefficients to examine the relationship between the neuromyths and GKN. The results showed no significant correlation between neuromyths and GKN $(r=-0.052, p=0.412, n=253)$.

\section{Regression Results}

The results showed that the variables school type (key school or general school) $(\beta=0.693, p=0.024)$ and headmasters' professional qualifications $(\beta=0.365, p=0.049)$ can significantly predict neuromyth scores (see Table 2). The key school headmasters were more likely to believe in neuromyths than the general school headmasters, whereas the headmasters with higher-level diplomas were less likely to believe in neuromyths than those with lower-level diplomas. Other than these two variables, no other factors (number of years teaching, school location, or GKN scores) predicted the prevalence of neuromyths. The fitted model explains a significant proportion of the variance in the data $\left[R^{2}=0.039, F_{(8,242)}=2.485, p=0.044\right]$.

\section{DISCUSSION}

The present study investigated the prevalence and predictions of neuromyths as well as GKN among school headmasters in Gansu province, China.

It is no surprise that although most of the headmasters (92\%) lacked professional training in neuroscience, $88 \%$ of the participants thought that neuroscience was useful for pedagogy. This finding was similar to the trend shown in a meta-analysis of different countries, which has found high proportions both in interest in neuroscience (98.5\%) and in its usefulness for teaching (95.4\%). The proportion of teachers who received information about neuroscience through in-training courses $(16.9 \%)$ or other sources was higher than that of the headmasters in our study $(8 \%)$ (Marta et al., 2016).

However, it may be problematic that the headmasters who were interested in neuroscience also received low scores in correctly disagreeing with neuromyths. The headmasters might be eager to implement their brain-based knowledge (as the data showed) in classrooms, while the knowledge should be neuromyths that is harmful to school education (Dekker et al., 2012). The interesting part is, although $95.4 \%$ of the headmasters thought neuroscience is useful for education and intend to implement such research results into classroom, the supplementary part of the questionnaire showed that almost no headmasters actually implement the findings. This because they do not know the best way to do so. Unfortunately, the data showed that most headmasters showed enthusiasm for neuroscience knowledge based on brain research without having official training, although such training is essential to eliminate neuromyths (Ansari et al., 2011; Nouri, 2013). Although the majority of educators admitted the importance and utility of neuroscience for educational practice, there is still a gap between the two areas (OECD, 2002; Pasquinelli, 2012). If policy makers perceive no clear and effective ways of implementing neuroscientific findings in the classroom, then they might limit investment in neuroscience-related training, which in turn would negatively affect teachers' knowledge of neuroscience and how they apply the knowledge in classrooms. To build a bridge between the laboratory and the classroom, requires properly educating teachers about neuromyths (Ansari and Coch, 2006).

\section{Prevalence of Neuromyths and General Knowledge of Neuroscience}

Regarding the prevalence of neuromyths and GKN, the results showed that the headmasters in Gansu province believed some neuromyths and misconceptions about neuroscience also recorded in Europe and eastern China. The proportions of those incorrectly believing neuromyths were very similar to those found in the meta-analysis conducted by Ferrero and colleagues (Marta et al., 2016): learning styles, the rich environment for preschool children, and exercise for improvement of brain function might be the most widespread and "classic" neuromyths (Kelly et al., 2017). Some researchers attribute such neuromyths to commercial educational packages (Marta et al., 2016), but among the headmasters we interviewed, almost none said that they had heard of any commercial products related to neuroscience, such 
TABLE 1 | Percentage of correct neuromyths.

\begin{tabular}{|c|c|c|c|c|c|}
\hline Statements & Strongly agree & Agree & Disagree & Strongly disagree & Correct \\
\hline $\begin{array}{l}\text { 1. Individuals learn better when they receive information in their preferred } \\
\text { learning style. }\end{array}$ & $207(81.8)$ & $28(11.1)$ & $10(4.0)$ & $6(2.4)$ & $16(6.4)$ \\
\hline 2. Environments that are rich in stimuli improve the brains of pre-school children. & $155(61.3)$ & $59(23.3)$ & $22(8.7)$ & $10(4.0)$ & $32(12.7)$ \\
\hline $\begin{array}{l}\text { 3. Differences in hemispheric dominance (left brain, right brain) can help explain } \\
\text { individual differences among learners. }\end{array}$ & $133(52.6)$ & $84(33.2)$ & $23(9.1)$ & $11(4.3)$ & $34(13.4)$ \\
\hline $\begin{array}{l}\text { 4. Exercises that rehearse co-ordination of motor-perception skills can improve } \\
\text { literacy skills. }\end{array}$ & $135(53.4)$ & $78(30.8)$ & $22(8.7)$ & $15(5.9)$ & $37(14.6)$ \\
\hline $\begin{array}{l}\text { 5. Short bouts of co-ordination exercises can improve integration of left and } \\
\text { right hemispheric brain function. }\end{array}$ & $119(47.0)$ & $82(32.4)$ & $31(12.3)$ & $18(7.1)$ & $49(19.4)$ \\
\hline $\begin{array}{l}\text { 6. It has been scientifically proven that fatty acid supplements (omega- } 3 \text { and } \\
\text { omega-6) have a positive effect on academic achievement. }\end{array}$ & $76(30.0)$ & $91(36.0)$ & $39(15.4)$ & $46(18.2)$ & $85(33.6)$ \\
\hline $\begin{array}{l}\text { 7. Children must acquire their native language before a second language is } \\
\text { learned. If they do not do so, neither language will be fully acquired. }\end{array}$ & $91(36.0)$ & $42(16.6)$ & $50(19.8)$ & $62(24.5)$ & $112(44.3)$ \\
\hline 8. We use only $10 \%$ of our brain. & $86(34.0)$ & $46(18.2)$ & $62(24.5)$ & $58(22.9)$ & $120(47.4)$ \\
\hline 9. Children are less attentive after consuming sugary drinks and/or snacks. & $46(18.2)$ & $75(29.6)$ & $51(20.2)$ & $78(30.8)$ & $129(51.0)$ \\
\hline $\begin{array}{l}\text { 10. Extended rehearsal of some mental processes can change the shape and } \\
\text { structure of some parts of the brain. }\end{array}$ & $64(25.3)$ & $76(30.0)$ & $46(18.2)$ & $63(24.9)$ & $140(55.3)$ \\
\hline $\begin{array}{l}\text { 11. Learning problems associated with developmental differences in brain } \\
\text { function cannot be remediated by education. }\end{array}$ & $41(16.2)$ & $52(20.6)$ & $66(26.1)$ & $90(35.6)$ & $156(61.7)$ \\
\hline 12. Regular drinking of caffeinated drinks reduces alertness. & $79(31.2)$ & $80(31.6)$ & $47(18.6)$ & $43(17.0)$ & $159(62.8)$ \\
\hline $\begin{array}{l}\text { 13. If pupils do not drink sufficient amounts of water ( } 6-8 \text { glasses a day), their } \\
\text { brains shrink. }\end{array}$ & $32(12.6)$ & $55(21.7)$ & $66(26.1)$ & $100(39.5)$ & $166(65.6)$ \\
\hline $\begin{array}{l}\text { 14. There are critical periods in childhood after which certain things can no } \\
\text { longer be learned. }\end{array}$ & $34(13.4)$ & $39(15.4)$ & $56(22.1)$ & $123(48.6)$ & $179(70.7)$ \\
\hline $\begin{array}{l}\text { 15. Individual learners show preferences for the mode in which they receive } \\
\text { information. }\end{array}$ & $167(66.0)$ & $58(22.9)$ & $18(7.1)$ & $7(2.8)$ & $225(88.9)$ \\
\hline
\end{tabular}

TABLE 2 | Predictors of Neuromyths.

\begin{tabular}{lcccccc}
\hline & \multicolumn{1}{c}{$\boldsymbol{B}(\mathrm{SE})$} & $\boldsymbol{t}$ & $\boldsymbol{p}$ & \multicolumn{2}{c}{$\mathbf{9 5 \%} \mathbf{C l}$ for $\boldsymbol{B}$} \\
\cline { 5 - 7 } & & & & \multicolumn{2}{c}{ Lower } & Upper \\
\hline (Constant) & $4.141(0.992)$ & 4.174 & 0.001 & 2.187 & 6.095 \\
Learning year & $0.365(0.185)$ & $1.979^{*}$ & 0.049 & 0.002 & 0.729 \\
Curriculums & $0.209(0.160)$ & 1.301 & 0.194 & -0.107 & 0.525 \\
Key or common & $0.693(0.306)$ & $2.265^{\star}$ & 0.024 & 0.090 & 1.295 \\
School location & $-0.067(0.228)$ & -0.295 & 0.768 & -0.516 & 0.382 \\
\hline
\end{tabular}

${ }^{*} p<0.05$

as Brain Gym, which are commonly used in some countries. The lower popularity of neuroscience-related products was found not only in the less developed areas of China but also in eastern China, the richest area of the country (Pei et al., 2015). In the interviews, the headmasters admitted that their knowledge of neuroscience came from their own experience, yet most could not recount the exact information source.

Regarding GKN, especially the mind-brain relationship, our data differed from those of some previous studies showing that teachers more strongly believe in biological programming than in environmental influence (Howard-Jones et al., 2009). In the present study, the headmasters in Gansu province more strongly favored an environment affecting students' achievement. According to the questionnaire, more than $80 \%$ believed that the environment, including exercise, can

shape children's mental abilities. That belief occurred because most of the headmasters are materialistic who believed in material determines consciousness, thus influencing their beliefs regarding the classroom. Their thoughts about mind and brain development being more open to influence from the environment and exercise might have both advantages and disadvantages in the classroom. On the one hand, they will devote themselves to education, because they believe that the environment, such as the school, can shape the students' minds and brains; on the other hand, they should be cautious in how the children are influenced because of the existence of neuromyths that might have negative effects on them (Pasquinelli, 2012).

\section{Predictors of Neuromyths}

The results of the present study suggested that more years of education might protect headmasters from believing in neuromyths, in contrast to the findings of some previous studies (Dekker et al., 2012; Deligiannidi and Howard-Jones, 2015; Im et al., 2018). The finding that participants with more educational background were more accurate regarding both neuroscience facts and myths may indicate that a liberal education leads to a better understanding of neuroscience by improving the ability to distinguish between scientific facts and myths. The reason that education was a protective factor against neuromyths may be complex. According to the participants' selfstatements when they filled out the questionnaire, experience was their main source of information. Although it is difficult to 
determine the relationship between education and experience, we could not simply infer that educational background was the predictor of belief in neuromyths. To better understand the relationship between neuromyths and educational background, future research should explore these issues.

In addition to educational background, school type might predict belief in neuromyths. Somewhat unexpectedly, headmasters of common schools believed in fewer neuromyths than headmasters of key schools. However, key school headmasters were more accurate in identifying genuine knowledge of neuroscience. One possible reason is that headmasters of key schools have more resources and opportunities to acquire brain-related knowledge, but without professional training, they are prone to assimilate neuromyths alongside neuroscientific facts. As previous research showed that taken educational psychology course only improve the general knowledge on neuroscience while can't reduce belief in neuromyths, which implied that education worked as a protective factor against only if it related directly to neuromyths (Im et al., 2018). The headmasters in key school have no experience on specific neuromyths education, but with more chance to acquire neuroscience information. Besides, neuromyths were usually easy to be understood and easy to be applied in the classroom, which lead key school headmasters prone to believe.

\section{REFERENCES}

Ansari, D., and Coch, D. (2006). Bridges over troubled waters: education and cognitive neuroscience. Trends Cogn. Sci. 10, 146-151. doi: 10.1016/j.tics.2006.02.007

Ansari, D., Coch, D., and De Smedt, B. (2011). Connecting education and cognitive neuroscience: where will the journey take us? Edu. Phil. Theory 43, 37-42. doi: 10.1111/j.1469-5812.2010.00705.x

Bangerter, A., and Heath, C. (2004). The mozart effect: tracking the evolution of a scientific legend. Br. J. Soc. Psychol. 43, 605-623. doi: 10.1348/0144666042565353

Chen, A. (2002). Urbanization and disparities in China: challenges of growth and development. China Econ. Rev. 13, 407-411. doi: 10.1016/S1043-951X(02)00098-6

Dekker, S., Lee, N. C., Howard-Jones, P., and Jolles, J. (2012). Neuromyths in education: prevalence and predictors of misconceptions among teachers. Front. Psychol. 3:429. doi: 10.3389/fpsyg.2012.00429

Deligiannidi, K., and Howard-Jones, P. A. (2015). The neuroscience literacy of teachers in Greece. Proc. Soc. Behav. Sci. 174, 3909-3915. doi: 10.1016/j.sbspro.2015.01.1133

Hongshan, H. (2012). Research on Selection Institution for Primary and Secondary School Principals. M.A. Thesis, Southwest University, Chongqing.

Hook, C. J., and Farah, M. J. (2013). Neuroscience for educators: what are they seeking, and what are they finding? Neuroethics 6, 331-341. doi: $10.1007 /$ s12152-012-9159-3

Howard-Jones, P. A. (2014). Neuroscience and education: myths and messages. Nat. Rev. Neurosci. 15, 817-824. doi: 10.1038/nrn3817

Howard-Jones, P. A., Franey, L., Mashmoushi, R., and Liao, Y. C. (2009). “The neuroscience literacy of trainee teachers," in British Educational Research Association Annual Conference, 1-39. University of Manchester.

Im, S. H., Cho, J. Y., Dubinsky, J. M., and Varma, S. (2018). Taking an educational psychology course improves neuroscience literacy but does not reduce belief in neuromyths. PLoS ONE 13: e0192163. doi: 10.1371/journal.pone.0192163

Kelly, M., Laura, G., Alida, A., Joanna, C., and Mcgrath, L. M. (2017). Dispelling the myth: training in education or neuroscience decreases but does not eliminate beliefs in neuromyths. Front. Psychol. 8:1314. doi: 10.3389/fpsyg.2017.01314
In summary, the present study found that most headmasters in Gansu province in northwestern China were interested in neuroscience and believed that education must benefit from neuroscience. While the headmasters believed in neuromyths that were widespread in developed countries; the specific performance of this sample believed in more neuroscience statement related to the environment affection and less statement related to the commercial products. Educational background and school type might be a predict factor for headmasters' neuromyths. Unfortunately, identifying the predictors of neuromyths is complicated, and these issues cannot be resolved immediately. Because neuromyths were common among the headmasters, educators should be cautious in applying laboratory results in the classroom. It is advisable for teachers and especially headmasters to be alert when they encounter neuroscience-related products.

\section{AUTHOR CONTRIBUTIONS}

AZ and RZ: contributed conception and design of the study. YJ: organized the database. RZ: performed the statistical analysis and wrote the first draft of the manuscript. BD: read and made main changes of the first draft. All authors contributed to manuscript revision, read and approved the submitted version.

Marta, F., Pablo, G., and Vadillo, M. A. (2016). Neuromyths in education: prevalence among spanish teachers and an exploration of cross-cultural variation. Front. Hum. Neurosci. 10:496. doi: 10.3389/fnhum.2016.0 0496

Ministry of Education of the People's Republic of China (2013). Condition of Fixed Assets and Teaching Resources. Available online at: http://old.moe.gov.cn/ publicfiles/business/htmlfiles/moe/s8494/201412/181980.html

Nouri, A. (2013). Practical strategies for enhancing interdisciplinary collaboration in neuroeducational studies. Int. J. Cogn. Res. Sci. Eng. Educ. 1, 94-100.

OECD (2002). Understanding the Brain: Towards a New Learning Science. Paris: OECD Publishing.

Oliver, M. (2011). Towards an understanding of neuroscience for science educators. Stud. Sci. Edu. 47, 211-235. doi: 10.1080/03057267.2011.604478

Pasquinelli, E. (2012). Neuromyths: why do they exist and persist? Mind Brain Edu. 6, 89-96. doi: 10.1111/j.1751-228X.2012.01141.x

Pei, X., Howard-Jones, P. A., Zhang, S., Liu, X., and Jin, Y. (2015). Teachers' understanding about the brain in East China. Proc. Soc. Behav. Sci. 174, 3681-3688. doi: 10.1016/j.sbspro.2015.01.1091

Rato, J. R., Abreu, A. M., and Castro-Caldas, A. (2013). Neuromyths in education: what is fact and what is fiction for Portuguese teachers? Edu. Res. 55, 441-453. doi: 10.1080/00131881.2013.844947

Tardif, E., Doudin, P. A., and Meylan, N. (2015). Neuromyths among teachers and student teachers. Mind Brain Edu. 9, 50-59. doi: 10.1111/mbe. 12070

Conflict of Interest Statement: The authors declare that the research was conducted in the absence of any commercial or financial relationships that could be construed as a potential conflict of interest.

Copyright (c) 2019 Zhang, Jiang, Dang and Zhou. This is an open-access article distributed under the terms of the Creative Commons Attribution License (CC BY). The use, distribution or reproduction in other forums is permitted, provided the original author(s) and the copyright owner(s) are credited and that the original publication in this journal is cited, in accordance with accepted academic practice. No use, distribution or reproduction is permitted which does not comply with these terms. 